\title{
ANALISIS RESPON MAHASISWA TERHADAP PERKULIAHAN DARING DI PRODI BIOLOGI STKIP PI MAKASSAR
}

\author{
Nur Amaliah Akhmad \\ STKIP Pembangunan Indonesia Makassar \\ nuramaliah02@gmail.com
}

\begin{abstract}
Analysis of Student Responses to Online Lectures in Biology Study Program STKIP PI Makassar. This research focuses on Basic Physics and Bhiophysics courses, which are carried out online using several applications, namely google classroom, Whatsaap, ZOOM, Google meet and Telegram. The purpose of this study is to determine student responses during the online learning process carried out in the odd semester of 2020/2021. Online lectures have been carried out 12 times by using zoom as face-to-face media and google classroom as a means of sharing material and individual assignments. Data collection techniques using google form questionnaires and quantitative descriptive data analysis. Based on the analysis carried out based on the responses of the Biology study program students of STKIP PI Makassar, that online learning is less effective in increasing student understanding in learning.
\end{abstract}

Keyword : online learning, basic physics, biophysics, response

\begin{abstract}
Abstrak: Analisis Respon Mahasiswa terhadap Perkuliahan Daring di Prodi Biologi STKIP PI Makassar. Penelitian ini terfokus pada matakuliah Fisika Dasar dan Biofisika yang dilakukan secara daring dengan menggunakan beberapa aplikasi yaitu google classroom, Whatsaap, ZOOM, Google meet dan Telegram.Tujuan dari penelitian ini untuk mengetahui respon mahasisswa selama proses pembelajaran online dilaksanakan di semester ganjil tahun 2020/2021. Pelaksanaan perkuliahan secara daring telah dilaknasakan sebanyak 12 Kali pertemuan dengan menggunkan zoom sebagai media tatap muka dan google classroom sebagai sarana pembagian materi dan tugas individu. Teknik pengumpulan data dengan menggunakan angket google form dan dilakukan analisis data deskriptif kuantitatif. Berdasarkan analisa yang dilakukan berdasarkan respon mahasiswa Prodi Biologi STKIP PI Makassar , bahwa pembelajaran daring kurang efektif dalam meningkatkan pemahaman siswa dalam belajar.
\end{abstract}

Kata kunci : pembelajaran daring, fisika dasar, biofisika, respon 
Masa pendemi COVID-19 ini memaksa semua kalangan agar mampu mengerjakan sesuatu tanpa harus keluar dari rumah salah satunya proses pembelajaran baik di sekolah maupun di kampus. Berdasarkan Siaran Pers Nomor :137/sipres/ A6/VI/2020 bahwa metode pembelajaran di semua zona wajib dilakukan secara daring untuk matakuliah teori sedangkan untuk matakuliah praktik juga sedapat mungkin dilakukan secara daring. Namun jika tidak dapat dilakukan secara daring maka diarahkan untuk dilakukan di akhir semester dengan tetap mematuhi protokol kesehatan.

Terkait pembelajaran daring ini tentu tidak semua dosen di Indonesia mampu melakukan pembelajaran daring dengan optimal. Hal ini tentu terkendala dengan aplikasi yang digunakan, jaringan yang tidak memadai, perangkat belajar yang tidak memadai atau bahkan beberapa dosen memang tidak paham menggunakan aplikasi online dalam pembelajarannya. Beberapa penelitian telah dilakukan untuk melihat beberapa respon dikalangan mahasiswanya diantaranya (Widayanti, 2020) menjelaskan pada penelitianya bahwa dengan pembelajaran daring ternyata efektif dalam proses pembelajaran dimasa pandemic ini.

Penelitian lain yang menjelaskan bagaimana motivasi belajar mahaiswa selama pembelajaran daring dijelasn oleh Fitriyani, Y., Fauzi, I., \& Sari, M. Z. (2020) bahwa tidak ada alasan bagi mahasiswa untuk tidak memiliki motivasi dalam belajar. Walaupun keadaaan sedikit lebih sulit dibanding pembelajaran tatap muka secara langsung.

Pembelajaran yang sedikit sulit dilakukan secara daring adalah matakuliah fisika dasar tentu dengan pembelajaran ini memerlukan waktu yang tidak sedikit dalam menjelaskan apalagi pemahaman rumus. Penelitan yang dilakukan oleh S. Basri (2018) mengatakan bahwa fisika perlu cara yang tepat agar mudah dipelajari oleh siswa. Sejalan dengan penelitian tersebut NA Akhmad (2019) mengatakan bahwa pembelajaran sains jika diberikan secara teori saja makan akan tidak tersampaikan maknanya kepada siswa. Ditahun yang sama NA Akhmad (2019) memaparkan bahwa kesulitan belajar peserta didik perlu di perhatikan dalam pembelajaran Sains oleh karena itu diperlukan metode yang bisa mengkolaborasikan antara teori dan praktek agar bisa dipahami siswa.

Oleh karena itu penelitian ini bertujuan untuk melihat bagaimana respon mahasiswa selama pembelajaran daring di lingkup STKIP PI Makassar khususnya untuk pembelajaran fisika dasar dan biofisika baik dari efektifitas dan efesiensi, tanggung jawab mahasiswa dalam melakukan tugas melalui daring.

\section{METODE PENELITIAN}

Metode yang digunakan dalam penelitian ini adalah metode kuantitatif. Pengambilan data dilakukan dengan angket google form dan dianalisa dengan data deksriptif kualitatif. Penelitian mengambil sampel sebanyak 82 orang dari 3 kelas pada 2 angkatan 2020 dan 2019. Penelitian ini dilaksanakan pada bulan April-Desember Tahun 2020.

\section{PEMBAHASAN}

\section{Efesiensi dan Efektifitas Pembelajaran Online}

Hasil respon dari penelitian ini sebanyak 82 orang mahasiswa yang memberikan respon angket dengan pernyataan " Apakah pembelajaran online ini lebih efesien dari pembelajaran tatap muka" adapun hasil tanggapann terlihat dari diagram dibawah ini .
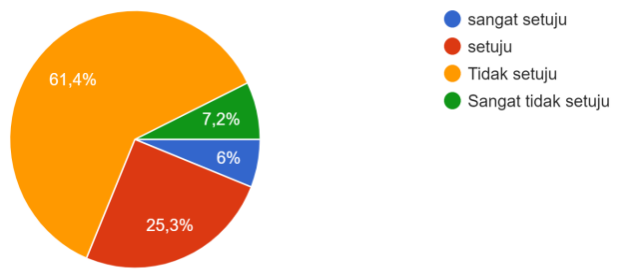

\section{Gambar 1. Efesiensi Pembelajaran Daring dibandingkan pembelajaran Tatap Muka}

Berdasarkam gambar 1 diatas, terlihat bahwa sebanyak 61,4\% mahasiswa tidak setuju dengan pembelajaran online dan mengakatan bahwa pembelajran secara online tidak efesien dan hanya sebanyak 6\% mahasiswa yang mengatajan bahwa pembelajaran online ini efesien. Sedangkan sebanyak 25,3 \% mahasiswa mengatakatan bahwa mereka setuju dengan pembelajaran online ini dan efesien bagi mereka. Sisanya sebanyak $7,2 \%$ yang 
tidak setuju dengan pembelajran online dilaksanakan.

Sedangan Tanggapan mahasiswa mengenai kefektifan pembelajaran online tertuang pada pernyataan "Pembelajaran online efektif dibandingkan pembelajaran tatap muka “ . Hasil Tanggapan Mahasiswa tertuang pada diagram dibawah ini

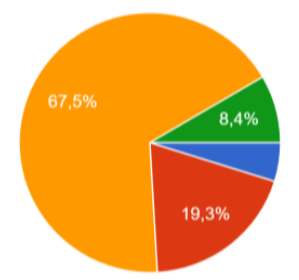

$$
\begin{aligned}
& \text { sangat setuju } \\
& \text { setuju } \\
& \text { Tidak setuju } \\
& \text { sangat tidak setuju }
\end{aligned}
$$

Gambar 2 . Efektifitas Pembelajaran Daring dibandingkan pembelajaran Tatap Muka

Dari gambar 2 diagram diatas terlihat sebanyak $67,5 \%$ mahasiswa tidak setuju dengan kefektifan pembelajaran daring, sebanyak $8,4 \%$ mahasiswa mengatakan sangat tidak setuju dengan pembelajaran daring dilaksanakan atau tidak efektif bagi mereka. Namun ada sebanyak $19,3 \%$ mahasiswa menggangap bahwa pembelajaran daring ini efektif dalam proses pembelajaran mereka di kelas.

\section{Tanggung jawab dan Ketepatan waktu dalam Pembelajaran Online}

Selama pembelajaran online ini dilaksanakan mahasiswa diajak bepacu dengan waktu, karena dengan aplikasi online yang digunakan waktu bisa diatur batas pengumpulannya berdasarkan hari, jam bahkan detik nya. Oleh karena itu untuk melihat tanggung jawab mahasiswa dalam mengerjakan tugas maka digambarkan pada gambar 3 diagram dibawah ini.

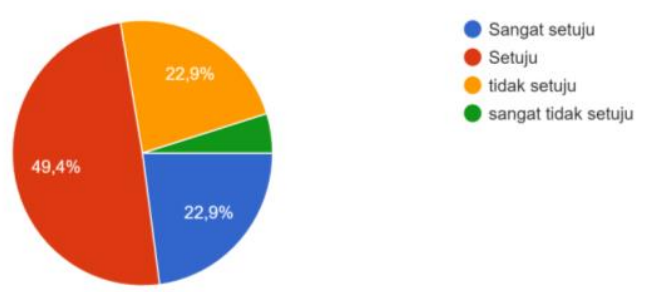

Gambar 3. Pembelajaran Online Mengajarkan Lebih Bertanggung Jawab dalam Belajar Mandiri

Berdasarkan gambar 3 diatas maka dapat ditarik kesimpulan bawa sebanyak 49,4\% mahasiswa mengatakan bahwa pembelajaran secara online ini dapat mengajarkan mahasiswa lebih bertanggung jawab dalam menyelesaikan masalah dalam belajarnya. Sedangkan sebanyak 22,9\% mengajatakan mereka sangat setuju bahwa pembelajaran online dapat melatih tanggung jawab mereka dalam belajar secara mandiri dirumah. Sisanya sebanyak $22,9 \%$ merasa pembelajaran online ini tidak menjadi tolak ukur rasa tanggung jawab didiri mereka dalam belajar mandiri dirumah.

Sedangkan untuk melihat ketepatan siswa dalam mengerjakan pekerjaan rumahnya secara online tertuang pada gambar 4 diagram dibawah ini:
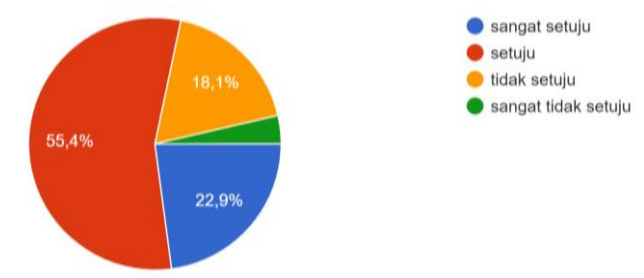

Gambar 4. Pembelajaran Online dapat melatih Ketepatan waktu dalam mengerjakan Tugas Secara Mandiri

Berdasarkan gambar 4 diatas maka terlihat sebanyak 55,4\% mahasiswa setuju bahwa pembelajaran online ini melatih ketepatan mereka dalam mengerjakan tugas dirumah. Sedangkan sebanyak 22,9\% mahasiswa mengatakan bahwa mereka sangat setuju dengan pembelajaran online dalam melatih ketepatan waktu mereka dalam belajar . Namun ada 18,1 \% mahasiswa tidak setuju dengan ketepatan waktu dalam mnegerjakan tugas mereka di rumah.

Oleh karena itu untuk melihat bagaimana respon siswa dalam pembelajaran online dan melihat apakah mereka setuju dilakukan pembelajaran online seterusnya. Gambaran pernyataan mereka dituang pada gambar 5 dibawah ini. 
Karst : Jurnal Pendidikan Fisika dan Terapannya Volume 3 | Nomor 2 | 65 p-ISSN: 2622-9641 e-ISSN: 2655-1276

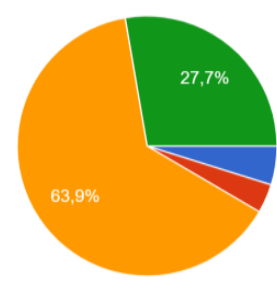

sangat setuju setuju tidak setuju sangat tidak setuju

Gambar 5. Pembelajaran Online dapat dilakukan Seterusnya.

Walaupun pembelajaran online dapat meningkatkan tangung jawab dan ketepatan mahasiswa dalam mengerjakan tugas secara online namun sebanyak 63,9\% mahasiswa ternyata tidak setuju dilaksanakannnya pembelajaran online seterusnya. Sedangkan sebanyak $27,7 \%$ sangat tidak setuju dengan pelaksanakan kuliah online selanjutnya .

Berdasarkan hasil yang diperoleh diatas maka pertanyaan lanjutan dilakukan untuk mengetahui kendala mereka dalam belajar online. Beberapa kendala mahasiswa dalam belajar online berdasarkan yang mereka tulis antara lain : Jaringan yang tidak stabil, kuota standar yang dimiliki mahasiswa walupun ada pembagian namun terbatas, Perangkat elektronik yang tidak mendukung, dan beberapa mahasiswa menjelaskan bahwa mereka tidak paham materi yang diajarkan secara online .

Walaupun pembelajaran online telah sukses merubah cara belajar di masa pandemi covid-19 namun banyak hambatan yang ditemui selama proses pembelajaran. Artinya pembelajaran secara online ini belum siap

\section{DAFTAR PUSTAKA}

Agustin, Mubiar. 2011. Permasalahan Belajar dan Inovasi Pembelajaran. Bandung: Refika Aditama.

Akhmad, N. A., \& Karim, S. (2019). The Application of Accelerated Learning Method Assisted by a Media Playing Card to Improve Learning Outcomes and Interesting Learning in Science Students of SMP Negeri 1 Barru. Jurnal Pendidikan Fisika, 7(3), 277-290.

Akhmad, N. A. (2019). ANALISIS KESULITAN BELAJAR PESERTA DIDIK TERHADAP PROSES PEMBELAJARAN IPA PADA KELAS VIII SMP NEGERI 1 BARRU. Karst: JURNAL PENDIDIKAN FISIKA DAN TERAPANNYA, 2(2), 60-63. dilaksanakan. Banyaknya mahasiswa yang berasal dari pelosok membuat pembelajaran online ini sulit dilaksanakan. Secanggih apapun alat dan aplikasi yang digunakan jika tidak ditunjang dengan prasarana maka proses pembelajaran online ini pasti akan terhambat. Apalagi mahaiswa STKIP PI Makassar banyak yang berasal dari pelosok daerah contohnya daerah Papua, Nusa Tenggara dan juga berada di pedalaman Sulawesi.

\section{PENUTUP}

Dari hasil analisis diatas dapat disimpulkan bahwa walaupun pembelajaran online ini memberikan kemudahan dalam belajar namun ternyata pembelajaran secara online ini bisa dibilang belum efektif dan efesien dalam pemahaman siswa dalam belajar. Pembelajaran online disisi lain mampu meningkatkan rasa tanggung jawab siswa dalam belajar mandiri dan mengajarkan mereka lebih tepat waktu dalam menyelesaikan tugas. Namu ternyata mahasiswa tidak menginginkan pembelajaran online secara terus menerus dilaksankan. Karena banyaknya faktor penghambat mereka dalam belajar diantaranya Jaringan, Perangkat elektronik dan kuota untuk online mereka terbatas. Oleh karena itu Pembelajran online ini perlu di kaji secara dalam dengan menggunkan aplikasi yang mudah dan bisa diakses oleh mahasiswa dimana saja

Basri, S., \& Akhmad, N. A. (2018). Penggunaan Metode Bermain Snakes And Ladders pada Pembelajaran IPA Fisika untuk Meningkatkan Minat Belajar Peserta Didik. Jurnal Pendidikan Fisika, 6(3), 309-323.

Fitriyani, Y., Fauzi, I., \& Sari, M. Z. (2020). Motivasi Belajar Mahasiswa Pada Pembelajaran Daring Selama Pandemik Covid-19. Jurnal Kependidikan: Jurnal Hasil Penelitian dan Kajian Kepustakaan di Bidang Pendidikan, Pengajaran dan Pembelajaran, 6(2), 165-175.

Widayati, S., Hotimah, N., \& Rakhmawati, N. I. S. (2020). Respon Mahasiswa Pada Proses Pembelajaran Mata Kuliah Daring. Child Education Journal, 2(1), 48-52 